\title{
"ÉS FEITICEIRO, ENTÃO JÁ ESTUDAS": CRIANÇAS EM RISCO, AGENCIALIDADE E MOBILIDADE SOCIAL EM ANGOLA
}

\author{
Pedro Pestana Soares ${ }^{1}$ \\ ${ }^{1}$ CRIA - Centro em Rede de Investigação em Antropologia, \\ Faculdade de Ciências Sociais e Humanas, \\ Universidade NOVA de Lisboa, Portugal
}

Nas últimas duas décadas, o clássico tema da feitiçaria na África subsaariana tem emergido com redobrado vigor tanto no meio académico como, através da comunicação social, no espaço público mais abrangente. Em grande medida, esta visibilidade advém de um fenómeno ${ }^{1}$ que, para a generalidade dos antropólogos e para muitos atores locais, tem uma origem muito recente: as acusações de feitiçaria a crianças. De fato, ainda que a associação das crianças a uma ampla diversidade de poderes espirituais esteja largamente documentada em muitos sistemas religiosos africanos, a encarnação moderna deste fenómeno, na sua vertente urbana e em larga escala, só parece surgir na literatura científica durante a década de 90 do século passado, assumindo particular visibilidade com a "epidemia" de feitiçaria entre os mais de 20.000 meninos de rua em Kinshasa, na República Democrática do Congo (Cimpric 2010:14-15). Desde então, vários casos na África Ocidental têm atraído a atenção dos mass media e das organizações não governamentais, alimentando um certo tipo de "discurso de abjeção" relativamente às consequências nefastas da globalização em solo africano, onde a propagação de igrejas neopentecostais surge como principal bode expiatório - discurso do qual parte da comunidade científica parece participar (ver, por exemplo, o volume coletivo organizado por La Fontaine em 2016, The Devil's Children). 
Em Angola, a questão das "crianças-feiticeiras" começou a ser construída enquanto problema social a partir do ano 2000 (Pereira 2008:31), quando foram identificadas várias centenas de crianças a viver nas ruas de Mbanza Kongo, capital da província do Zaire, aparentemente expulsas ou fugidas de casa na sequência de acusações de feitiçaria. Estes e outros casos surgidos nos anos seguintes, não só no Norte do país mas também em Luanda, têm alimentado um debate no espaço público angolano que questiona a sobrevivência de elementos "atávicos" na Angola moderna, em contramarcha com a visão progressista proposta pela ideologia de Estado. Neste quadro, tem assumido um papel central o estatuto da etnia bakongo, na qual parece ocorrer a generalidade destes casos, e que, para alguns atores nesse processo, representa o polo oposto - etnocêntrico, religioso, tradicional - de uma visão hegemónica que propõe a modernidade, a transetnicidade e o laicismo como modelo de cidadania. ${ }^{2}$

As entidades governamentais têm implementado algumas estratégias concertadas para desencorajar estas acusações (a Rede de Protecção à Criança na província do Zaire, por exemplo) e intervindo de forma repressiva junto de igrejas neopentecostais que realizam procedimentos agressivos de "limpeza" espiritual. Contudo, têm sido principalmente as congregações missionárias católicas que se encarregam de acolher a maior parte dos acusados que vivem nas ruas, numa grande diversidade de contextos de institucionalização que têm como objetivo a reintegração das crianças na família e na sociedade. $O$ presente trabalho debruça-se sobre o processo de reintegração social e familiar de crianças acusadas de feitiçaria acolhidas por duas instituições missionárias em Angola, onde realizei trabalho etnográfico a partir de 2013. Partindo de uma abordagem inicial assumidamente exploratória, a emergência e a análise do material etnográfico fez com que o foco de análise fosse progressivamente se centrando nas transformações de estatuto e nos novos papéis da infância e juventude em Angola, em linha com os padrões identificados em outros países da África Ocidental no período pós-Guerra Fria.

\section{Modernidade e crianças-feiticeiras na África subsaariana}

Embora o enquadramento da feitiçaria enquanto fenómeno da modernidade tenha, nos últimos anos, estado menos presente no discurso académico (Kroesbergen-Kamps 2020), os textos sobre a "modernidade da feitiçaria", e principalmente a obra basilar de Geschiere (1997), continuam a informar a generalidade do discurso académico sobre o tema. Em África, como noutros contextos geográficos, a feitiçaria é entendida como um meio pelo qual as populações rurais e urbanas confrontam os problemas 
contemporâneos, um contínuo argumento sobre os aspetos funcionais, morais e éticos de fenómenos como o capitalismo, a globalização e as relações internacionais, no qual participam múltiplas vozes, em múltiplos contextos (Englund 1996). Seguindo a leitura da escola de Manchester, que concebia a feitiçaria como um mecanismo de gestão de tensões (Marwick 1964) e de recuperação de uma ordem social ameaçada, esse argumentário surgiu como reação às novas estruturas socioeconómicas que, pela mão dos colonos, eram implantadas nos territórios ultramarinos e conduziam à fragmentação das instituições, normas de conduta, códigos morais e visões do mundo "tradicionais".

Já no período pós-colonial, muitos autores interpretaram esse ressurgimento como uma resposta à vaga de neoliberalismo que varreu o continente africano desde o final da década de 80 e aos efeitos da globalização que se começaram a sentir por essa altura (Comaroff \& Comaroff 1993; Geschiere 1995). Contudo, mais do que uma resposta, a feitiçaria é lida neste contexto como uma espécie de metáfora crítica dessa globalização, como um comentário às suas consequências patológicas nas sociedades africanas (Comaroff 1997; Parish 2000; Meyer 1992). Ela adequa-se, por exemplo, aos mecanismos obscuros de acumulação de poder e riqueza que substituíram o financiamento das duas superpotências depois da queda do Bloco de Leste, e que se implantaram mercê de uma orgânica "oculta" aos olhos do cidadão comum (Rowlands \& Warnier 1988; Fisiy \& Geschiere 1993). Muitas das narrativas de feitiçaria (e também de zombies, canibais e caçadores de cabeças) das últimas décadas parecem também aludir às relações predatórias de consumo na sociedade globalizada, estabelecendo paralelismos evidentes entre bens de consumo e pessoas (ou partes delas) e entre riqueza material e força vital (Scheper-Hughes 1996).

O fenómeno das "crianças feiticeiras" é geralmente considerado um exemplo cabal da complexa interação da crença na feitiçaria com os efeitos desestruturantes da modernidade nas sociedades africanas. Se, para as ONGs que encontram o fenómeno no terreno, as acusações contra crianças são uma estratégia legitimada por instâncias tradicionais, religiosas e culturais para aliviar o fardo económico das famílias, reduzindo o número de dependentes no agregado familiar (Cimpric 2010:22-23), os antropólogos que se têm debruçado sobre estes casos afastam-se de uma explicação puramente economicista e apontam um conjunto mais complexo de fatores causais.

Filip De Boeck $(2000,2004)$, no trabalho etnográfico que tem realizado nos últimos vinte anos em Kinshasa, na República Democrática do Congo (RDC), considera que a pobreza é um elemento determinante para a emergência do fenómeno das crianças feiticeiras, mas assegura que ela não é 
suficiente para a compreender. Na génese desta crise estão também muitos outros elementos ligados a formas complexas de insegurança social e espiritual na capital da RDC. Esta nova conjuntura engloba a redefinição das redes de parentesco nos grandes centros urbanos (com as consequentes alterações nas formas de circulação dos filhos), as transformações no "alcance" da feitiçaria, que transcende a esfera social mais restrita da família e se torna mais aleatória e perigosa, uma drástica e súbita transformação no estatuto, visibilidade e poder das crianças e jovens que ameaça as estruturas preexistentes de autoridade e gerontocracia, e as novas (e mais eficazes) formas de combate à insegurança espiritual oferecidas pelas igrejas neopentecostais que têm proliferado nas últimas décadas.

O enquadramento contextual de De Boeck para a situação na RDC é o mais abrangente dos realizados até a data sobre o fenómeno contemporâneo das crianças feiticeiras, mas outros estudos apontam para a existência de fenómenos afins em Camarões, Nigéria, Malawi e República do Congo (Brain 1970; Pirot 2004; Van der Meer 2013; Yengo 2008). Falta referir, evidentemente, o contexto geográfico mais relevante para este estudo, o das províncias angolanas de Zaire, Uíge e Cabinda, no norte de Angola, e da capital do país, Luanda.

\section{Angola: feiticeiros vindos do Norte}

\section{A especificidade bakongo}

Se em Kinshasa, como sublinhou De Boeck, este fenómeno é transversal a todos os estratos sociais, incluindo os étnicos, em Angola ele parece estar circunscrito à etnia bakongo (Pereira 2011:187; Pérez 2006:17-18). Os bakongo, que são cerca de um milhão, constituem em termos numéricos o terceiro maior grupo etnolinguístico de Angola e ocupam tradicionalmente as três províncias norte-ocidentais do país (Zaire, Uíge e Cabinda), estendendo-se ainda para o norte, pela República Democrática do Congo (RDC), e para noroeste, pela República do Congo (Fonseca 1989:21-22). Esta distribuição geográfica resulta numa intensa mobilidade interfronteiriça uma espécie de "nação transnacional" bakongo - em que a língua comum, as redes de solidariedade e os laços de parentesco secundarizam a importância das fronteiras políticas. A memória do antigo Reino do Kongo, cujo território coincidia, grosso modo, com o atualmente ocupado pela etnia, perdura ainda e serve de matéria-prima para o enraizamento dos bakongo numa "comunidade 
imaginada" que muitas vezes entra em conflito com a cartografia pós-colonial desta região africana. A identidade bakongo que daí emerge, e que contempla com frequência uma peculiar religiosidade de cariz profético, não se opõe propriamente a uma identidade angolana, mas antes constrói diferentes (e por vezes inventivos) significados do que implica ser angolano, significados estes que podem colidir com a versão de angolanidade defendida e disseminada pelo regime (Sarró, Blanes \& Viegas 2008: 87).

Em Luanda, procurei auscultar perceções e significados da problemática da criança-feiticeira junto da União Tradicional Kongo, uma associação que congrega líderes comunitários e ativistas bakongo chegados à capital durante os anos da guerra civil (1975-2002). Os meus interlocutores, na sua maioria anciãos cujas vidas se repartiram entre a província angolana do Zaire, a República Democrática do Congo e Luanda, ofereceram-me a sua leitura do fenómeno numa visão informada não só pela cosmologia bakongo, mas também pela experiência de quem já testemunhou estes acontecimentos nas suas comunidades, e mesmo nas suas famílias.

\section{Transgressão, predação e a mercantilização da feitiçaria bakongo}

Tal como me foi dada a conhecer na União Tradicional Kongo, a feitiçaria infantil na sua atual configuração - ou seja, enquanto "epidemia" - é uma variante perversa, filtrada pelas patologias da contemporaneidade, dos mecanismos tradicionais de transmissão de poder espiritual nas linhagens matrilineares bakongo. Nesta etnia, o poder espiritual (kindoki ou ndoki) é geralmente transmitido do tio materno para um sobrinho num ritual de "entronização" realizado por um operador do sagrado especializado (nganga nzombo), permanecendo latente ou submetido ao próprio poder do tio enquanto este é vivo. Após a sua morte, o kindoki passará a ser usado pelo novo chefe de família na proteção da sua linhagem (kanda), estando a sua ação circunscrita ao contexto familiar. Mas, para além deste mecanismo tradicionalmente sancionado, existe um outro tipo de transmissão de poder espiritual que viola as leis da matrilinearidade bakongo e que constitui, segundo os meus interlocutores, "um crime grave". Trata-se da transmissão do kindoki por via patrilinear, de pai para filho biológico - algo que vem assumindo maior expressão com a cada vez maior preponderância das famílias nucleares e o crescente poder dos pais biológicos nas sociedades africanas pós-coloniais. Nesta configuração, a transmissão do kindoki quebra a interdição que circunscrevia estes poderes à linhagem materna e 
criava uma barreira à sua disseminação, e passa então a assumir um caráter predatório: "o pai que dá feitiço é um pai homicida, assassino, quer roubar almas na família deste menino".

Nas últimas décadas, a expansão das redes de sociabilidade associada às frequentes migrações dos bakongo, à sua deslocação para os centros urbanos e às transformações na dinâmica das próprias cidades angolanas levaram esse processo a assumir formas cada vez mais imprevisíveis e desreguladas. O feitiço pode agora ser transmitido por vizinhos ou meros desconhecidos encontrados na rua, através de transações que evocam o caráter mercantilizado das economias neoliberais: o kindoki é passado à criança através de um bem de consumo (uma bolacha, por exemplo) oferecido num encontro aparentemente fortuito. Posteriormente, durante a noite, o feiticeiro adulto encontra-se com a criança em sonhos e pede-lhe que retribua a oferenda com a vida de alguém, em geral um familiar da própria criança (o termo mais utilizado, evocando a função alimentar da oferenda que a colocou em dívida, é "comer" essa pessoa). Em face da inadequação dos mecanismos tradicionalmente validados para resolver estes fenómenos em contexto intrafamiliar, as comunidades afetadas tendem a "improvisar" soluções extremas que levam, não raras vezes, à morte das crianças acusadas ou à sua expulsão do núcleo familiar. O papel das igrejas neopentecostais nesse processo é ambíguo, proporcionando, por um lado, um ambiente mais protegido e controlado para o exorcismo mas, por outro, reforçando o imaginário da feitiçaria como força omnipresente no quotidiano dos fiéis e associando todas as manifestações de poder espiritual ao domínio do diabólico.

\section{Crianças da noite, crianças dos espíritos}

A cosmologia tradicional bakongo, bem como a de outros povos bantos, concebe o mundo de forma antitética, postulando pares de elementos ou dimensões opostas entre si que se sucedem ciclicamente. Temos, por exemplo, o binómio dia/noite, que corresponde ao de mundo dos vivos/ mundo dos mortos, e de mundo dos homens/mundo dos espíritos (Bortolami 2012:315-317; MacGaffey 1974:418). A associação do período noturno às atividades das potências ocultas, nas quais os homens participam através dos sonhos, continua a marcar o imaginário da feitiçaria bakongo mesmo nos contextos urbanos e contemporâneos, como foi evidente ao longo do meu trabalho de campo. Para os elementos mais velhos da União Tradicional Kongo, é a atividade onírica, e não o estado de vigília, que permite aceder 
à verdadeira etiologia dos acontecimentos quotidianos. É no mundo dos espíritos, da noite, que se encontram as causas últimas dos infortúnios (ou das venturas) que sucedem durante o dia aos homens mortais: "os que estão a dormir - isso é um provérbio bakongo - os que estão a dormir podemos considerá-los como pessoas, mas nós que estamos de pé, acordados, somos cegos. A razão é simples: o Homem, o ser humano, vê tudo à noite, mas não de dia. É onde existe a dificuldade da feitiçaria".

Em cidades como Luanda, Kinshasa ou Mbanza Kongo, onde as acusações de feitiçaria e outros fatores levaram muitas crianças a fugir de casa para viver nas ruas, estas tornaram-se, de certa forma, donas de uma mobilidade privilegiada durante o período noturno. À noite, as crianças reúnem-se em locais preestabelecidos - aqueles que os trabalhadores sociais chamam "focos" - onde socializam, trocam bens de consumo e estabelecem complexas hierarquias de poder entre si. O mundo noturno, onde, nas grandes cidades africanas, a presença humana está quase ausente ou é relegada para o domínio da marginalidade, torna-se assim a casa e o recreio dessas crianças, um local de degredo, mas também, paradoxalmente, de liberdade - e essa liberdade de movimentos durante a noite, um período associado ao mundo espiritual e ao domínio dos mortos, é para muitos bakongo evidência de que as crianças de rua mantêm uma relação próxima com o sobrenatural.

Invasão, contaminação e outros discursos de alteridade

Apesar de os regressados bakongo serem, segundo Nzatuzola (1997), academicamente mais qualificados do que a média da população angolana (na qual, segundo o Censo de 2014,48\% da população adulta não tinham nenhum nível de escolaridade concluído), a forma como a dimensão religiosa permeia o quotidiano bakongo continua a ser lida por outras etnias, e principalmente pelas comunidades urbanas e letradas, como um "atavismo" que colide com o imaginário de modernidade e progresso projetado pelo Estado para o futuro da nação angolana. Para além disso, certos aspetos do mundo espiritual bakongo - particularmente os conceitos de kindoki ou ndoki, agora já entendidos como "feitiço" e não apenas como "poder espiritual", e ainda mais as acusações de feitiçaria endereçadas a crianças - são apresentados pela comunicação social e pelos porta-vozes de entidades governamentais como produto de uma "invasão estrangeira" oriunda do vizinho ao Norte que penetra no território nacional através das redes transnacionais bakongo. 
Esta retórica, que recorre com frequência a conceitos epidemiológicos de "contágio" e "contaminação", acaba por resultar numa dinâmica de hostilidade perante a "invasão congolesa" e em frequentes ações repressivas contra as consequências percecionadas dessa invasão: o comércio informal, a acelerada proliferação religiosa e certas formas de pequena criminalidade (ver, por ex., Human Rights Watch 2002, 2003). Essas supostas consequências também legitimam, em parte, as medidas que o Estado tem desenvolvido no terreno para combater as acusações de feitiçaria a crianças, sejam estratégias concertadas de intervenção social, como os Comités de Proteção da Criança na província do Zaire, sejam as pontuais (mas mediáticas) ações repressivas da Polícia Nacional junto de igrejas em Luanda que praticam rituais de libertação em crianças acusadas.

Esta típica instrumentalização dos "discursos de feitiçaria" (Fancello \& Bonhomme 2018:588) no reforço das lógicas de justificação dos diversos atores não escapa também à religião (nominalmente) majoritária em Angola. De facto, a Igreja Católica tem alinhado o seu discurso com o do Estado, sublinhando os efeitos sociais perversos destas manifestações de "religiosidade primitiva" e a sua inadequação ao processo de reconstrução nacional, embora tenda a não acentuar a suposta origem estrangeira do fenómeno ou a sua exclusividade étnica (ver, por ex., Mata Mourisca 2003). Nos últimos anos, as autoridades eclesiásticas preocuparam-se fundamentalmente em regular as práticas e as crenças da própria comunidade católica, pressionadas por declarações públicas da Santa Sé. O próprio papa Bento XVI, aquando da sua visita a Angola em 2009, pronunciou-se asperamente a respeito dos cristãos que "vivem com medo dos espíritos, de poderes nefastos que os ameaçam, desorientados, e chegam a condenar crianças de rua e até idosos, porque, dizem, são feiticeiros". Perante nova advertência do Vaticano aos bispos da Conferência Episcopal de Angola e São Tomé (CEAST), em 2011, a Igreja angolana estipulou no ano seguinte "penas de interdição e suspensão temporárias a todos aqueles fiéis leigos, religiosos e religiosas e sacerdotes que recorrerem e fomentarem a prática da feitiçaria" (CEAST 2012:35). ${ }^{3}$

\section{Assistencialismo católico e juventude}

Muitos clérigos católicos - principalmente os que integram congregações missionárias - conhecem de perto a problemática das acusações de feitiçaria a crianças. A ação assistencialista da Igreja junto das populações mais jovens ganhou particular expressão no período de guerra 
civil, quando missões e outras instituições católicas atuaram em regime de emergência nas diversas províncias angolanas, procurando abrigar as crianças dos bombardeamentos, acolher as que ficavam órfãs ou sem casa, e encaminhá-las para locais mais seguros - geralmente Luanda - através de pontes aéreas ou do restabelecimento ocasional das vias de comunicação terrestre. Na própria capital, quando em meados dos anos 90 o número de crianças deslocadas das províncias chegou a atingir 4.500, as instituições católicas de Luanda tiveram um papel determinante na absorção desse grande afluxo de crianças.

Na segunda metade da mesma década, a Igreja acrescentou a valência educativa a várias casas de acolhimento, introduzindo cursos de formação profissional em lares e orfanatos católicos mediante um acordo entre o cardeal Alexandre do Nascimento e o presidente José Eduardo dos Santos (Neves 2012:220). Por esta altura, as características da população de crianças sem abrigo começavam a mudar, fruto da diminuição do afluxo de refugiados às cidades, da reintegração familiar das crianças que tinham chegado no início dos anos 90 e da emergência de um novo problema social que conduzia ao abandono do lar: as acusações de feitiçaria contra crianças entre os bakongo que, nas décadas anteriores, se tinham deslocado das províncias do Norte para Luanda. Assim, as instituições de acolhimento católicas passaram também a receber as crianças-feiticeiras que deambulavam pelas ruas de Luanda e das províncias do Zaire e Uíge, lidando com esta nova problemática à luz dos mecanismos a que já tinham recorrido para reintegrar nas suas famílias as crianças fugidas da guerra. ${ }^{4}$

O trabalho etnográfico em que o presente estudo se alicerça foi realizado em duas instituições geridas por congregações missionárias masculinas. Uma delas foi provavelmente a que, no campo do acolhimento de crianças de rua, maior visibilidade alcançou na capital angolana durante as últimas décadas: o Centro de Acolhimento de Crianças Arnaldo Janssen, fundado em 1993 por missionários da Ordem do Verbo Divino e das Servas do Espírito Santo. A outra instituição sob escrutínio é o Centro de Acolhimento Frei Giorgio Zulianello, criado em Mbanza Kongo em 2002 pela comunidade de franciscanos capuchinhos residente na capital da província do Zaire. Fugindo do padrão habitual neste tipo de instituições, o CAFGZ não surgiu como resposta ao problema das crianças deslocadas ou desalojadas pela guerra, mas está desde a sua génese ligado à questão das crianças-feiticeiras. 


\section{Reabilitando feiticeiros entre Luanda e Mbanza Kongo}

\section{O Centro de Acolhimento de Crianças Arnaldo Janssen (Luanda)}

Quando cheguei a Luanda no início de 2013, o terreno etnográfico deste projeto cingia-se ao Centro de Acolhimento de Crianças Arnaldo Janssen (CACAJ), uma instituição de assistência à infância e juventude constituída como associação e gerida pela congregação católica Missionários do Verbo Divino (Societas Verbi Divini, SVD). Este centro de acolhimento localiza-se no limite oriental do bairro Palanca, um aglomerado urbano de construção informal ("musseque") que se desenvolveu sobretudo durante os anos 80 e 90, com o grande afluxo de deslocados vindos do Norte que procuravam em Luanda refúgio da guerra civil, e que continua ainda hoje a exibir uma dinâmica cultural, económica e religiosa de matriz predominantemente bakongo.

O meu objetivo inicial era caracterizar a atividade do sector social do CACAJ na reintegração familiar das crianças residentes - em particular as acusadas de feitiçaria - nas suas famílias de origem, focando a minha atenção na dimensão étnica que, segundo o trabalho desenvolvido por Luena Pereira $(2008,2011)$ poucos anos antes, informava de maneira determinante a dinâmica das acusações de feitiçaria a crianças em Angola. Os contactos que já estabelecera a partir de Lisboa permitiram-me, logo à chegada, aceder facilmente aos responsáveis pelas várias valências da instituição, com os quais agendei entrevistas que acabaram por abarcar a maioria dos técnicos e dirigentes do centro de acolhimento. O CACAJ que encontrei durante esse período lutava ainda por sobreviver aos dramáticos cortes de apoio e financiamento de ONGs e outros organismos internacionais com que trabalhara desde a sua génese, em 1992, até o final da guerra civil, em 2002, quando o cessar-fogo levou os principais agentes internacionais de assistência humanitária a retirar Angola das suas prioridades de investimento.

A partida do seu fundador e principal dinamizador, o padre argentino Horácio Caballero, em 2007, também tinha deixado marcas na instituição. Durante 15 anos, o padre Horácio mobilizara recursos e criara uma poderosa rede de contatos entre o "mundo assistencialista" de Angola. O seu extraordinário carisma parecia ainda gerir fantasmaticamente o Centro Arnaldo Janssen, vulgarizado entre a população como "Centro de Padre Horácio" e cujo logotipo - a efígie do santo alemão e fundador da ordem verbita, Arnaldo Janssen (1837-1909) - era tido habitualmente como o retrato do próprio padre argentino. 
Apesar destas crises perturbarem o trabalho dos assistentes sociais (tornando os procedimentos-tipo mais lentos e fragmentários), tive oportunidade de participar em diversas fases do processo de acolhimento e reintegração das crianças, incluindo a assistência noturna aos meninos que pernoitam nas ruas da cidade - e que funciona como uma espécie de "recrutamento" para novos internos - e as consultas de acompanhamento psicológico, realizadas já nas instalações do CACAJ. Durante esse período, contactei informalmente alguns dos 130 rapazes acolhidos no centro, embora as narrativas pessoais sobre acusações de feitiçaria tenham sido recolhidas junto de interlocutores mais velhos - ex-internos que, entretanto, já no final da adolescência, passaram a trabalhar no departamento de formação do CACAJ.

O CACAJ não tem instalações que permitam pernoitar fora das camaratas dos próprios residentes, pelo que não pude residir na instituição durante a minha permanência em Luanda. Ao invés, residi na missão dos Franciscanos Capuchinhos da paróquia de $\mathrm{N}^{\mathrm{a}}$ Senhora de Fátima, onde me foi dada a conhecer a existência de um centro de acolhimento de crianças gerido por esta ordem religiosa na capital da província do Zaire, Mbanza Kongo, onde o historial da maioria das crianças residentes estaria marcado por acusações de feitiçaria. Aceitei o convite para visitar esta instituição, o Centro de Acolhimento Frei Giorgio Zulianello (CAFGZ), reconhecendo aqui uma oportunidade para introduzir um elemento comparativo no estudo e conhecer de perto um dos pontos nevrálgicos do território autóctone bakongo, a antiga capital do reino do Kongo.

\section{O Centro de Acolhimento Frei Giorgio Zulianello (Mbanza Kongo)}

O Centro de Acolhimento Frei Giorgio Zulianello localiza-se a $3 \mathrm{~km}$ do centro de Mbanza Kongo, à beira da estrada que liga esta cidade à povoação do Luvo, na fronteira com a República Democrática do Congo, apenas 50 km a Norte. É através desta via de comunicação que se processa grande parte do trânsito (legal e ilegal) entre Angola e a RDC, ligando os vários pontos do quotidiano bakongo, não só dentro da própria "nação Kongo", mas estendendo-se também, mais ao sul, à "diáspora" em Luanda. Durante a minha estadia nesta instituição, as questões da mobilidade transfronteiriça revelaram-se fulcrais para a orgânica do CAFGZ, que recebe cada vez mais crianças trazidas pela Polícia Nacional, depois de detidas sem documentação válida (geralmente acompanhadas por "imigrantes ilegais" adultos) quando em trânsito entre a RDC e Angola. Este tipo de problemática tem assumido 
cada vez maior expressão nos últimos anos, representando agora, a par com as acusações de feitiçaria, uma das principais causas de institucionalização das crianças. À data do trabalho etnográfico, o Centro acolhia 57 crianças e adolescentes, tanto rapazes quanto raparigas, embora com uma grande preponderância (cerca de 80\%) do sexo masculino.

Em Mbanza Kongo fui acolhido pela congregação que gere o Centro Frei Giorgio Zulianello (os Franciscanos Capuchinhos) e fiquei alojado na missão franciscana, a poucos metros do mesmo, pelo que pude complementar os dados recolhidos nas entrevistas aos técnicos e dirigentes da instituição com um acompanhamento mais próximo do quotidiano do CAFGZ. Aqui, o dia a dia na missão articula-se intimamente com o funcionamento do centro de acolhimento, não só devido à proximidade geográfica, mas também porque os frades que constituem a congregação integram os quadros do CAFGZ. Se, por um lado, isto conduz a uma maior estabilidade de recursos humanos e a um acompanhamento mais próximo dos internos, a situação muito periférica de Mbanza Kongo dificulta a fixação de outros quadros mais qualificados.

O relativo isolamento de Mbanza Kongo reflete-se também na diminuta presença de organizações assistencialistas não governamentais e faz com que o próprio Estado seja a única alternativa para o estabelecimento de parcerias, tanto em termos de financiamento e apoio material (financiando a construção de instalações, por exemplo) quanto em termos do suporte à própria orgânica da instituição, fortemente dependente da articulação com a Polícia Nacional, o Instituto de Apoio à Criança e o Ministério da Assistência e Reinserção Social. Por outro lado, o panorama religioso muito diversificado de Mbanza Kongo - em que uma multiplicidade de novas igrejas proféticas e neopentecostais coexiste com a adoção generalizada de crenças e práticas religiosas ditas "tradicionais" - atenua a presença concreta da Igreja e dos missionários no quotidiano das populações. Nas palavras do diretor da CAFGZ, "aqui somos apenas uma ilha".

Os dados recolhidos nestes dois terrenos etnográficos de Luanda e Mbanza Kongo permitiram reconhecer um processo faseado de acolhimento e reintegração das crianças que, apesar das diferentes tónicas na abordagem, pode ser tipificado em quatro fases. 


\section{Encaminhamento}

O processo pelo qual as crianças chegam a estas duas instituições é bastante distinto. Na capital, é o CACAJ que mobiliza uma equipa (afeta à ONG Samu Social, que trabalha em parceria com o centro de acolhimento) para visitar as crianças de rua em diversos "focos" onde elas se reúnem para pernoitar. Essa equipa (que geralmente integra uma psicóloga e um médico) desloca-se numa carrinha afeta a esta função e procura mobilizar os jovens para se deslocarem voluntariamente ao centro e serem aí acolhidos, realizando com eles várias atividades de sensibilização e prestando cuidados médicos. Já em Mbanza Kongo, é a Polícia Nacional que se encarrega de assumir a custódia de crianças em situação de risco referenciadas às autoridades por se encontrarem num estado de particular fragilidade - é o caso das crianças acusadas de feitiçaria que vivem nas ruas da cidade, geralmente perto dos mercados - ou por serem interceptadas sem documentação válida (ou acompanhando um adulto nessas condições) quando em trânsito entre Angola e a República Democrática do Congo. A polícia encaminha então o menor para o Instituto Nacional da Criança (INAC), instituição sob tutela do Ministério da Assistência e Reinserção Social (MINARS), que a entrevista para determinar se a situação justifica o seu acolhimento no CAFGZ ou se, pelo contrário, é possível reinseri-la de imediato na família.

\section{Acolhimento}

Se, em Mbanza Kongo, o ingresso das crianças no centro de acolhimento é feito pela mão de organismos governamentais como o INAC ou a Polícia, em Luanda elas chegam à instituição por iniciativa própria (em resultado do trabalho de mobilização feito pelas equipas de rua, ou por a criança já conhecer o trabalho do CACAJ), ou levadas por terceiros, geralmente membros das suas famílias. Neste último caso, os familiares procuram proteger-se dos poderes sobrenaturais da criança ou proteger a própria criança da hostilidade de outros membros da família que a querem submeter a rituais agressivos de libertação espiritual.

No primeiro contacto com as instituições de acolhimento, é realizada com as crianças uma entrevista de anamnese (em Luanda, por um assistente social ou educador social, em Mbanza Kongo, pelo diretor do Centro) na qual se procura explorar o historial da criança, esclarecer de que forma ela saiu do núcleo familiar, quais os problemas que levaram a essa separação e qual 
o seu trajeto entre a casa de família e o centro. No decorrer da permanência da criança na instituição, posteriores entrevistas ou interações informais podem alterar essa informação, reformulando elementos da história pessoal do entrevistado.

\section{Localização e reunificação familiar}

A reunificação com a família de origem é, desde a fundação do CACAJ em inícios dos anos 90, um dos objetivos centrais da instituição. Ao contrário do que acontecia de início, em que as crianças e as famílias separadas pela guerra desejavam ativamente um reencontro, hoje em dia o processo torna-se mais problemático porque ambas as partes podem oferecer resistência: a família porque quer continuar salvaguardada da ameaça espiritual e do acréscimo de encargos que a criança representa, e a criança porque receia ser alvo de represálias ou voltar a sofrer procedimentos antifeitiçaria agressivos. Em Mbanza Kongo, pelo contrário, o ingresso de crianças acusadas de feitiçaria no CAFGZ pode marcar uma ruptura quase total com as famílias de origem. De facto, o seu acolhimento depende de uma rejeição explícita e formal por parte dos pais através da assinatura de uma "Declaração de Rejeição" em que a tutela é transferida para a instituição missionária. A cisão entre a criança e a sua família, como veremos, raramente é absoluta e definitiva, mas esta formalização perante as autoridades governamentais do INAC reflete, na perspetiva dos agentes de reinserção social, uma dinâmica de hostilidade entre ambas as partes dificilmente ultrapassável a curto ou médio prazo.

Na capital angolana, após a família de origem ser localizada, a intervenção da "equipa social" do CACAJ procura reduzir a insegurança espiritual que a criança representa para a família, restaurando os níveis de confiança entre ambos. Nesse processo, a estratégia utilizada pelos assistentes sociais da instituição mobiliza os próprios acusadores e transforma-os nos principais agentes de mudança, incentivando-os a sugerir soluções alinhadas com o seu sistema de crenças. Assim, os familiares são convidados a apresentar soluções satisfatórias para ambas as partes, ou seja, que eliminem o feitiço aos olhos dos acusadores e que não sejam agressivas ou traumáticas para a criança. Na concretização dessas soluções, que pode incluir a intervenção de um pastor ou curandeiro (kimbandeiro), é frequente os técnicos estarem presentes para assegurar que o procedimento seja inócuo para a criança. 


\section{Formação escolar e profissional}

A capacitação académica e profissional dos internos constitui, nas duas instituições estudadas, um elemento determinante para a reintegração bemsucedida destes jovens nas famílias e na sociedade. Tanto em Luanda como em Mbanza Kongo foram estabelecidas parcerias com o Ministério da Educação e com o Instituto Nacional de Ensino e Formação Profissional que permitem aos menores institucionalizados prosseguir os estudos em estabelecimentos do ensino oficial e frequentar cursos de formação profissional em entidades externas ao centro de acolhimento. As próprias instituições missionárias possuem também a valência de formação profissional, e o centro de Mbanza Kongo nasceu mesmo, após o cessar-fogo de 2002, com este objetivo principal: suprir as carências de capacitação académica e profissional dos jovens da província do Zaire, que durante a guerra tinham permanecido escondidos para não serem recrutados para o exército.

Em alguns casos, o sucesso escolar e profissional dos jovens institucionalizados facilita a reunificação familiar a longo prazo. Ambos os centros registam casos de famílias que, ao conhecerem o potencial de inserção no mercado de trabalho e a capacidade de gerar rendimentos de forma autónoma conquistados pelos jovens durante a permanência nas instituições, reclamam novamente a custódia dos filhos que anos antes tinham acusado de feitiçaria. Este facto reforça nos técnicos dos centros a crença de que a acusação de feitiçaria é um mecanismo culturalmente validado para aliviar os encargos das famílias através da expulsão dos seus membros mais vulneráveis.

\section{Agencialidade, autonomia e mobilidade}

\section{O fenómeno dos "falsos feiticeiros"}

Embora o processo de reintegração das crianças siga caminhos distintos nas duas instituições (a ênfase na reintegração familiar em Luanda, contrastando com a estratégia centrada na capacitação profissional em Mbanza Kongo), emergiu em ambos os terrenos um elemento comum que, segundo os meus interlocutores, tem assumido cada vez mais visibilidade nos últimos anos. Trata-se daquilo a que os técnicos sociais designam por "fenómeno dos falsos feiticeiros", e que corresponde a um crescente afluxo de crianças que procuram acolhimento dizendo ter sido acusadas de feitiçaria mas cujas causas de abandono do lar se revelam posteriormente serem outras. 
À partida, as razões que o justificam não parecem ser evidentes. Tendo em conta que as acusações de feitiçaria a crianças são um fenómeno tão traumático para os acusados, que parecem implicar rupturas com as redes familiares e sociais às quais as crianças estão ligadas, e que reforçam demarcações identitárias de cariz étnico, religioso e cultural potencialmente estigmatizantes, por que razão reportariam essas crianças acusações de feitiçaria que nunca existiram? Para uma das assistentes sociais do CAFGZ, em Mbanza Kongo, muitos relatos de acusações são fabricados pelas próprias crianças, como forma de escapar dos ciclos de pobreza em que se veem aprisionadas:

Os próprios meninos é que inventam, é uma forma de fugirem da família quando veem que não é um sítio digno para eles. Eles já conhecem o centro de Mbanza Kongo, então vêm aqui na rua, rondam, rondam... Então interpelamos os meninos e eles dizem "ah, somos acusados de feitiçaria". Então dizemos, "vai para o INAC" e o INAC envia para aqui. Aquela pena que o frei Danilo tem, caridade, ajuda os meninos e vêm parar aqui. Quando chegam cá, inventam que são feiticeiros. Mas há pessoas também que estão cá e que avisam. Os próprios meninos explicam o que eles devem dizer.

Os testemunhos dos técnicos e posteriores interações com as próprias crianças parecem confirmar que os residentes dos centros desempenham um papel ativo na construção de relatos fictícios desta natureza e no "recrutamento" de novos feiticeiros. Como os centros funcionam em regime semiaberto (durante um determinado período do dia as crianças podem aceder livremente ao exterior), os internos interagem de forma muito próxima com as crianças que se encontram ainda nas ruas e aconselham as que pretendem ser acolhidas sobre as estratégias com maior probabilidade de sucesso.

O sucesso das instituições missionárias e a sua mediatização ao longo da última década parecem então funcionar como chamariz para as crianças que enveredam por essa estratégia de ruptura, identificando-se um paralelismo entre o número crescente de "falsos feiticeiros" e a cada vez maior presença das próprias instituições em peças de jornalismo, nas quais surgem como recursos quase milagrosos capazes de transformar acusações de feitiçaria em oportunidades de ascensão social. Nas palavras de um assistente social de Luanda,

Na televisão passa que no CACAJ a criança tem pequeno-almoço, almoço e jantar, e as crianças estão de olho aberto a olhar para isso. Logo, para poder chegar ali, a criança tem de ir para a rua, porque estamos a dizer que vamos 
buscar as crianças à rua e vêm para o centro ser acolhidas. Lá em casa não tem matabicho, não tem almoço, não tem jantar, não tem brinquedo como a televisão mostra. Logo, tem de vir para a rua para dizer ao seu pai que você não presta, você não consegue comprar um brinquedo para mim.

Em Luanda, pude testemunhar a chegada à instituição de um dos "falsos feiticeiros" que me tinham sido referidos em entrevistas e conversas informais. Numa das minhas últimas visitas ao CACAJ, enquanto conversava com uma irmã Serva do Espírito Santo, aproximou-se de nós um adolescente que residia no centro há bastante tempo acompanhado por Moisés, uma criança que nunca tínhamos visto. Disse que o menino tinha 10 anos e acabara de chegar ao centro depois de passar uma longa temporada na rua, para onde fugira por ter sido acusado de feitiçaria pela família. A freira que me acompanhava disse-lhe para dar de comer à criança, enquanto o assistente social preparava a entrevista inicial. Terminada a conversa com a minha interlocutora, fui buscar o recém-chegado com o pretexto de lhe mostrar o trabalho dos Meninos Pintores de Angola, um grupo de internos que se dedica às artes plásticas. A criança contou-me então com grande desenvoltura que ambos os pais tinham morrido e que ele fora viver com uma tia. A tia acolheu-o muito a contragosto e começou a procurar pretextos para o expulsar de casa. Quando teve um acidente de viação atribuiu-o aos poderes nefastos e sobrenaturais de Moisés e a partir de então submeteu-o a diversos maus-tratos, incluindo cortes na cara com vidros partidos que causaram algumas cicatrizes bem visíveis. Fugira então para a rua, onde vivera algum tempo com outros rapazes até ouvir falar no CACAJ.

Apesar de algumas características da criança me parecerem discrepantes daquela narrativa - a aparência demasiado bem nutrida e asseada para alguém que passara vários dias na rua, a forma energética e até jovial como contava a sua história dramática - informei a irmã de que a história me parecia verídica e que achava a criança uma boa candidata a permanecer no centro. Foi por isso, com alguma surpresa, que, quando regressei ao CACAJ dois dias depois, me informaram que os pais do Moisés tinham comparecido no CACAJ para o irem buscar - a criança tinha afinal furtado alguns objetos em casa para vender, e fugira com medo das represálias. A história que ele contara tinha sido fabricada em conjunto com alguns amigos ex-utentes do centro, que já tinham confessado tê-la delineado alguns dias antes para maximizar as hipóteses de acolhimento.

Esta instrumentalização das acusações por parte das crianças, que as reclamam como veículo de agencialidade sobre o seu próprio futuro, parece contrastar intensamente com a forma como o fenómeno foi abordado na Europa após o surgimento de alguns casos de acusações de feitiçaria 
a crianças em comunidades congolesas e angolanas do Reino Unido. As respostas institucionais postas em marcha na sequência destes muito mediatizados episódios, incluindo a criação do National Working Group on Child Abuse Linked to Faith or Belief por parte do Ministério da Educação britânico (The National Working Group on Child Abuse Linked to Faith or Belief 2012), e as tomadas de posição da Direção Geral de Politicas Externas da União Europeia (Hanson e Ruggiero 2013) sublinham que as crianças desempenham, nesse processo, um papel essencialmente passivo.

Porém, a noção de que, em situações de crise, as crianças são prisioneiras de um estatuto vulnerável e dependente tem sido posta em causa por vários autores, que salientam a importância do contexto social em que elas se inserem para a definição desse estatuto e a urgência em adotar visões mais flexíveis sobre o lugar que elas ocupam e o poder de que dispõem. Esta perspetiva, tal como salienta Bordonaro (2012), surge na sequência da introdução da noção de agencialidade nos estudos sobre a infância por James e Prout (1990), tornando-se desde então recorrente na abordagem das ciências sociais à infância e adolescência, a par das críticas à tendência dos assistentes sociais e dos programas de reabilitação ou reinserção para subestimar a autonomia, a reflexividade e a resistência das crianças.

Em contextos considerados "de risco", os trabalhos de Horna Padrón e Balllet (2011), por exemplo, ilustram como uma significativa agencialidade pode ser reconhecida mesmo em crianças que vivem em circunstâncias dramáticas, incluindo as que vivem nas ruas. A emergência de crises sociais generalizadas é mesmo capaz de funcionar como catalisador dessa agencialidade: a desestruturação das famílias, a dissolução dos laços de solidariedade entre os seus membros e o colapso dos mecanismos de coesão social aumentam a autonomia das crianças e criam para elas lugares que antes não existiam. O papel do filho como sustento de família, ocupando no mercado laboral o lugar do pai que morreu na guerra, é um dos exemplos mais cabais desse novo poder, e um dos mais reconhecíveis nos contextos pósguerra da África Ocidental, e nomeadamente de Angola (Pereira 2011:192). Outros autores realçam a forma como os conflitos violentos em África afetam a infância e a juventude, examinando as complexas - e perversas - formas de agencialidade decorrentes da sua participação em gangs, em exércitos (as crianças-soldado) ou em grupos de extorsão (La Hausse 1990; Honwana 2002; Shepler 2005).

No caso concreto das crianças acusadas de feitiçaria, o trabalho de De Boeck (2000) com os meninos de rua de Kinshasa é, como já vimos antes, particularmente revelador, ao identificar diversos aspetos que refletem uma mudança significativa do estatuto das crianças na República Democrática 
do Congo. Um deles é a exploração do "dote sobrenatural" por parte da criança acusada de feitiçaria, que pode aceitar a acusação para denunciar um adulto responsável pelo seu enfeitiçamento e assim ganhar poder sobre essa pessoa. A confissão surge aqui como um mecanismo de retribuição, uma oportunidade para redistribuir a violência e o sofrimento entre o mundo dos adultos que, em última análise, pode levar ao linchamento dos indivíduos indicados como responsáveis pela transmissão do feitiço. Estas e outras formas de agencialidade são desenvolvidas por Honwana e De Boeck no seu já clássico estudo Makers and Breakers (2005), no qual os autores sublinham que as reformulações no estatuto dos jovens não decorrem apenas de contextos de violência e de caos social, nem resultam só em reconfigurações potencialmente disruptivas; elas demonstram também o papel ativo e criativo dos jovens africanos na conceção e na moldagem de novas práticas sociais e a sua capacidade de construir novas alternativas de futuro que não se limitam à emulação acrítica de padrões culturais importados do Ocidente.

Casa, rua, centro de acolhimento: mundos sociais de fronteiras fluidas

Se a manifestação de um certo grau de agencialidade por parte das crianças é transversal à diversidade de contextos em que vivem e crescem, as questões de marginalização social e de violência estrutural associadas a esses contextos vão inevitavelmente informar a configuração e a amplitude dessa agencialidade. Vários autores introduziram conceitos que procuram traduzir o impacto desses condicionalismos na agencialidade das crianças, incluindo o de "agencialidade fina" (Klocker 2007), "agencialidade tática" (Honwana 2005) ou "agencialidade protetora" (Atkinson-Sheppard 2017). Para Ungruhe (2019), contudo, formas de agencialidade muito circunscrita, como estas, não são suficientes para traduzir o potencial de operatividade evidenciado pelas crianças de rua, que se prende inescrutavelmente à sua capacidade de circular, de forma fluida, entre diversos locais e respetivos "mundos sociais".

No meu próprio trabalho de campo, tanto a "vida na rua" como a "vida no centro" e a "vida em casa" eram, de facto, várias facetas de um processo dinâmico através do qual as crianças atravessavam diversos domínios, desde a própria rua, até as instituições missionárias, a casa de família (ou de vários familiares), a escola e mesmo locais de trabalho. Esta fluidez permitia, por exemplo, que as crianças acusadas optassem por sair de casa para se juntarem a grupos de rua nos quais a viabilidade dessa solução já 
tinha sido confirmada. Um dos mais velhos residentes no CACAJ relatou da seguinte forma a decisão de abandonar a casa do tio-avô, após ter circulado por várias casas de familiares que o expulsaram repetidamente por temer os seus poderes sobrenaturais:

Um único tio-avô aceitou ficar comigo, mas a coisa era diferente, você podia acordar hoje e um parente materno vem a casa e diz, "olha, eu sonhei contigo, olha que tu vais morrer já". Até as pessoas que antes brincavam comigo agora sonhavam comigo. Então já não tinha alternativa, tinha assim um grupo de rapazes que vinham de Malange e costumavam ir tomar banho no Cacuaco, e eles perguntavam sobre mim e eu lhes contei. E eles usavam essa expressão, "olha, vão-te podar, é melhor desapareceres dali. Sai dali, olha que nem todos nós viemos para aqui só porque os nossos parentes morreram na guerra. Alguns dos nossos amigos também são acusados de serem ngapa" ('feiticeiro' em quimbundo).

Como já vimos, a mobilidade e a agencialidade encontram-se intimamente relacionadas no caso das crianças de rua que recorrem a estratégias "criativas" para serem acolhidas nos centros. É no encontro das crianças que vivem na rua com os residentes dos centros, em espaços sobrepostos de convivialidade que o regime semiaberto das instituições permite, que narrativas fictícias são construídas num esforço colaborativo que vai potenciar as hipóteses de acolhimento. A porosidade das fronteiras entre estes vários espaços foi-se tornando evidente ao longo do meu trabalho de campo, pondo também em causa o suposto isolamento das crianças acolhidas ou na rua em face do contexto familiar. Se, por um lado, passar a viver na rua era muitas vezes uma decisão racional e estratégica que não só permitia à criança escapar das ameaças iminentes de maus-tratos infligidos por membros da família, como lhe proporcionava melhores oportunidades de alcançar sucesso económico no futuro, a vida na rua - e posteriormente nos centros de acolhimento - implicava a manutenção de um determinado grau de ligação com familiares, passando amiúde pela recriação ou reconfiguração dessa rede de relações.

Samuel, um jovem de 13 anos que fora trazido ao centro de acolhimento em Mbanza Kongo pelo seu padrasto, acompanhado por um pastor evangélico que certificou ser a criança um feiticeiro, tinha delineado já um plano que resultaria, segundo os seus cálculos, no regresso ao seio familiar. Iniciara um curso de estudo bíblico acompanhado por um dos frades franciscanos residentes no centro, e visitava regularmente os seus pais na companhia do professor para lhes dar conhecimento do seu progresso no seio da fé cristã e lhes fazer ver que, gradualmente, se afastava da influência da feitiçaria. 
Também no CACAJ, em Luanda, as tensões entre as crianças acusadas de feitiçaria e as suas famílias não implicavam, geralmente, a constituição de barreiras herméticas entre a esfera familiar e o centro de acolhimento. António, um rapaz de 11 anos que fora acolhido após uma sessão de "limpeza espiritual" extremamente agressiva promovida pela mãe e pelo padrasto, identificara, entretanto, um tio paterno que talvez tivesse condições de o acolher, e visitava a sua casa regularmente na companhia da psicóloga do centro. Nesses encontros, a psicóloga apresentava os progressos da criança no nível da educação escolar e da formação profissional e artística, sublinhando que, através de uma educação cristã e de uma adequada supervisão, as suas "capacidades especiais" tinham sido reorientadas. As particularidades daquela criança, que antes a tornavam especialmente vulnerável à influência das forças ocultas, eram agora canalizadas para o desenvolvimento pessoal e para a capacitação.

\section{Prosperidade e mobilidade social: contrapartidas de uma miragem}

As dimensões que enquadram o contexto das crianças-feiticeira em Angola apresentam muitas continuidades relativamente à realidade da RDC. Mas a situação de certa estabilidade política e social e de acelerado crescimento económico registada em Angola desde o final da Guerra Civil - associadas a um discurso de Estado que projeta a prosperidade e a modernidade para o futuro próximo da nação - não se reflete, de todo, na realidade da República Democrática do Congo. Esta ênfase na capacitação, na educação e na formação de quadros que permeia o espaço público angolano a serviço de um progresso que, para a generalidade da população, parece ao mesmo tempo muito próximo e muito distante, é o que torna as instituições de acolhimento missionárias opções tão atraentes para os jovens.

Durante o período de guerra civil, a juventude angolana fora já alvo de atenção privilegiada por parte das duas grandes fações beligerantes. MPLAe UNITA desenvolveram estratégias de mobilização específicas para os jovens que, embora recorressem a mecanismos de manipulação e violência (no recrutamento de soldados, por exemplo) também lhes concederam um grau de autonomia até então inédito em certos círculos do meio político angolano (Parsons 2004:60). No entanto, em tempos de paz essas instâncias de poder revelaram-se infrutíferas. Nove anos após o final da guerra, Rodrigues (2010) auscultou as percepções da juventude angolana acerca das suas necessidades e aspirações, e concluiu que, para os jovens, a guerra os privou de um conjunto 
de recursos essenciais, principalmente ligados à educação e à capacitação profissional, que agora urge recuperar. O período de paz surge então como uma via de acesso aos benefícios da modernidade que deve ser percorrida o mais rapidamente possível para compensar as perdas dos anos de guerra e aproveitar o potencial que, aparentemente, o futuro encerra.

Instituições missionárias como as focadas no presente estudo parecem encerrar uma promessa de educação e formação livres de encargos económicos capaz de abrir as portas a esta via rápida para a prosperidade. Numa perspetiva puramente economicista, os moldes pelos quais se manifesta a agencialidade das crianças podem parecer promissores - capitalizando um fenómeno socialmente estigmatizante para criar oportunidades de mobilidade social de outra forma inacessíveis. Contudo, apesar de, como antes referido, a esfera familiar continuar a informar a sociabilidade da criança após a sua saída de casa, uma leitura mais crítica destas novas configurações sociais revela que elas podem ter resultados perversos porque acontecem à custa de um "colapso intergeracional" de crianças e adultos e do sacrifício de laços de proximidade em prol das exigências da economia e do mercado.

É o que indica um estudo baseado em entrevistas com crianças acusadas de feitiçaria na RDC (Ballet, Dumbi \& Lallau 2014), no qual os autores concluem que, na dialética de acusação à criança e contra-acusação da criança aos adultos, a primeira se torna, de facto, um poderoso agente no processo. Contudo, os custos desta agencialidade são muito elevados: para além de reforçar a crença na eficácia destrutiva da feitiçaria, ela contribui para a destruição da solidariedade intergeracional e acentua ainda mais o enfraquecimento de laços familiares já muito debilitados pela guerra, a pobreza e as migrações. Um dos fundadores do CAFGZ, frei Gabriele Bortolami, também concorda que esse tipo de autonomização "não é sempre positivo; nós podemos considerar isso nessa ótica, mas é um sinal da grande influência que a economia de mercado tem na mentalidade e na maneira de solucionar os problemas".

A aceitação desta "contrapartida" por parte das crianças - a de uma ruptura das redes de solidariedade familiares e comunitárias - parece surgir em consequência do abismo percecionado entre a prosperidade alcançada por uma elite muito minoritária e as reais probabilidades de aceder a esses privilégios. Não se trata apenas da enorme distância que as crianças reconhecem entre os dois polos desta sociedade acentuadamente desigual. É antes uma ostensiva impermeabilização das vias de acesso entre estes dois mundos que, para Ricardo Soares Oliveira (2007:614), tão bem caracteriza a Angola das últimas décadas, um país onde duas tendências paradoxais coexistem sem se intercetar: por um lado, um Estado incapaz de 
pôr em prática as suas competências sociais mais básicas e de responder às necessidades fundamentais da grande maioria da população, por outro, uma elite muitíssimo próspera, dotada de um exército típico de uma superpotência regional e de poderosas redes de apoio internacionais.

Também António Tomás (2012) alicerça a sua tese de doutoramento na ideia de disjunção entre as elites do Estado e a população, encarando-a como uma das características mais distintivas da sociedade angolana contemporânea e identificando uma ruptura radical em que ambas as partes se isentam de obrigações mútuas e constroem de forma quase autónoma os seus próprios sistemas económicos. Para quem nasce e vive aprisionado num dos lados da barricada, a esfera do poder e da opulência parece surgir então como um "outro mundo" de acesso tão difícil e improvável quanto o domínio do sobrenatural. O imaginário do oculto surge aqui não simplesmente como metáfora dos efeitos contraditórios do neoliberalismo (Comaroff \& Comaroff 1999:295), mas, mais concretamente, como forma de traduzir as particularidades do mundo "escondido" da política e da economia angolana, cujos mecanismos de acumulação parecem estar muito para além do alcance da generalidade dos angolanos. Parece assim mais fácil de compreender que o estatuto de feiticeiro se torne um instrumento propício à abertura de canais entre estes dois domínios e ao trânsito entre eles. A esfera do poder e da acumulação em Angola surge aqui quase como um deus absconditus, tão remoto e inacessível que só o recurso à teurgia pode garantir alguma probabilidade de acesso.

Entre os técnicos que trabalham nas instituições missionárias, há mesmo quem incentive as crianças a confiar na capacidade da feitiçaria para operar tais "milagres". A psicóloga de serviço no CACAJ, em Luanda, conta que, durante as sessões de aconselhamento com as crianças residentes, lhes comunica que "esses poderes também têm vantagens, eles te dão capacidades; és feiticeiro, então já estudas, já trabalhas, já pintas, tens educação". Esta estratégia parece tentar despojar o kindoki de uma valoração moral negativa que foi construída historicamente pelo olhar colonial e por processos mais recentes de urbanização extrema. Por um lado, o facto de as epistemologias tradicionais kongo associarem o kindoki à ideia de ingestão, de introduzir algo dentro do corpo, foi relacionado por autores europeus católicos aos atos e aos processos do envenenamento (Ballard 2005 citado em Blanes 2017). Por outro, e como salienta Blanes (2017), ao elaborar sobre as distinções entre kindoki positivo e negativo, é precisamente a transplantação do mundo kongo para cidades como Luanda, onde a «tradição» foi corrompida pelos processos de urbanização extrema, que vai reforçar a valoração moral na equação do kindoki. 
Esse processo moralizador articula-se segundo um conjunto plural e concorrencial de compreensões do kindoki em espaço urbano por parte de diversos agentes políticos e religiosos (majoritariamente cristãos), mas também é fruto de "um processo de comodificação, no estrito sentido marxista do termo, em que o kindoki é inserido num sistema capitalista, movido pelo dinheiro, que é característico da vida urbana" (:96). Assim, a intervenção da psicóloga do CACAJ vai reenquadrar o kindoki numa noção de feitiço mais próxima da tradição kongo, em que o dom hereditário do kindoki funcionava como mecanismo regulador da interação coletiva, de valoração ambígua e potencial multifacetado. De facto, para autores como Milando (2007:94-95) e Bortolami (2012:335-338), o kindoki pode exercer um efeito desagregador sobre as famílias e as comunidades e constranger o potencial de empoderamento individual e coletivo das populações; mas também pode ser visto como factor de empowerment - os numerosos relatos de façanhas heroicas dos combatentes independentistas contra a administração colonial, agindo supostamente sob a protecção do kindoki, são exemplo disso - e de nivelamento e homeostase social, encorajando a redestribuição de bens dentro das comunidades por temor de que o kindoki seja mobilizado como antídoto para o enriquecimento excessivo. Nas entrevistas que realizei com porta-vozes da comunidade bakongo em Luanda, este potencial capacitante e empoderador da feitiçaria foi claramente sublinhado.

Essas feitiçarias eram benignas, alguns as usavam como bênção para ser bem sucedido na caça, nas colheitas. Depende da orientação deste mesmo feitiço, do trabalho, da função que desempenha. Mas aquelas que aderiram à religião cristã, vieram retirando estes poderes, eliminando, banindo essa tradição. Porque essas religiões não quiseram reconhecer o feitiço de bem do feitiço de mal. Para eles, desde que é kindoki é mesmo kindoki. Não há faca da cozinha, toda a faca é um punhal.

Os desenvolvimentos mais recentes das acusações de feitiçaria a crianças parecem então traduzir um mecanismo de adaptação à modernidade e ao desenvolvimento assente num aparente paradoxo: um processo impulsionado por uma ideologia de ruptura com o passado, com a tradição e com a etnização - a ideologia materialista do Homem Novo e o liberalismo económico que lhe sucedeu - acaba por produzir um mecanismo de ascensão social cujo motor é um fenómeno em que se encontram plasmados esses três atributos: a herança histórica, as formas tradicionais de religiosidade e a valorização da etnia como marcador identitário. Para o discurso de Estado, a atávica e sobre-etnizada acusação de feitiçaria encerra em si tudo o que devia ter ficado no passado da 
nação angolana - a religiosidade mágica, a desigualdade social, a influência estrangeira - mas nas mãos destas crianças transformara-se num veículo de acesso à prosperidade que lhes era prometida mas sistematicamente negada.

Tal como noutros contextos da África Ocidental contemporânea, também aqui a esperança na erradicação das acusações de feitiçaria, acalentada pelos discursos oficiais dos regimes mais recentes, fracassou ostensivamente. Ao invés, estes fenómenos ressurgem agora com força redobrada, ainda que assumindo novas configurações que parecem traduzir - ou servir de metáforas para - as contradições da modernidade e do problemático acesso aos benefícios do progresso. Em boa verdade, a grande maioria da população angolana parece viver numa das "zonas cinzentas" com que Charles Piot (2010) caracteriza parte significativa da África Ocidental no período pósGuerra Fria: um território onde o Estado retrocedeu e abdicou das suas responsabilidades sociais, em que emergem novas estruturas de poder, mais difusas e instáveis, articuladas através da implantação de ONGs e de Igrejas Neopentecostais. Mas, ao contrário do que acontece noutros países (Piot debruça-se sobre o Togo), em que os Estados se viram privados do seu património após a retirada dos interesses internacionais, o Estado angolano não é propriamente um "regime de simulacro" vazio, alicerçado num jogo de aparências.

Se, para outras nações africanas, a modernidade e os seus benefícios estão na Europa e nos Estados Unidos - e a única forma de as alcançar é emigrar - em Angola são as cúpulas do Estado, com a sua acumulação de riqueza em circuito fechado, que surgiram nas últimas décadas como ideal de prosperidade. E, apesar de o acesso a estas esferas permanecer, na prática, vedado à esmagadora maioria da população, a propaganda governamental alimenta um imaginário em que a educação e a formação de quadros - necessárias para que o país possa dispensar a mão de obra estrangeira - abrem as portas à esfera da acumulação. Piot, ao caracterizar as mais recentes configurações da feitiçaria no Togo, relata como os modernos feiticeiros - tradicionalmente dotados da capacidade de voar - se deslocam agora durante a noite pelos céus africanos em direção à Europa, visitando as capitais luminosas do mundo ocidental e testemunhando o sucesso da diáspora togolesa. Desconhece-se se um levantamento da imagética relatada por "feiticeiros" angolanos produziria voos noturnos ao palácio presidencial ou à sede da Sonangol. Mas, apesar de exigir um custo social muito elevado, a feitiçaria surge agora para muitas crianças destas instituições missionárias como um veículo capaz de as transportar a um "outro mundo", um mundo que, podendo distar poucos metros do musseque onde vivem, continua a ser tão remoto quanto as grandes metrópoles europeias. 
Recebido em 25 de maio de 2020

Aprovado em 25 de agosto de 2021

Pedro Pestana Soares é doutorando em Antropologia na Universidade Nova de Lisboa, onde estuda as articulações transnacionais de movimentos islâmicos de inspiração sufi implantados em Portugal, abrangendo ainda terrenos etnográficos em Moçambique, Índia e Inglaterra. Em 2016 concluiu o mestrado em Antropologia no ISCTE-IUL, com uma etnografia de missões católicas angolanas que acolhem crianças acusadas de feitiçaria. Previamente, como membro da Númena-Centro de Investigação em Ciências Sociais e Humanas, trabalhou sobre religiões minoritárias e discriminação religiosa em Portugal e integrou a equipa multidisciplinar de "The Pilgrimage Project: A Study of Motivations and Experiences in Sacred Spaces", desenvolvendo trabalho de campo em vários locais de peregrinação cristã e neopagã na Europa.

https://orcid.org/0000-0002-7227-4209

Email: pestanasoares@gmail.com 


\section{Notas}

* Este artigo parte de trabalho de campo desenvolvido no âmbito do projeto "A Política da Esperança: o Papel das Igrejas na Reconstrução da Angola de Pós-guerra", financiado pela Fundação para a Ciência e Tecnologia (PTDC/CS-ANT/112897/2009).

1 Nota da revisora: No texto serão mantidas as pequenas diferenças que restaram entre o português de Portugal e outros países e o do Brasil, como algumas acentuações, por exemplo, conforme estabelecido pela Nova Ortografia.

2 Apesar de o fenómeno das "crianças-feiticeiras" estar praticamente circunscrito à etnia bakongo, o imaginário da feitiçaria e as acusações dirigidas a adultos são, no período contemporâneo, transversais a numerosas etnias de Angola e respetivos contextos geográficos, como, por exemplo, o Quando-Cubango (Brinkman 2003) e as Lundas (Calvão 2017).

3 O fato de este documento pastoral condenar o fomento da "prática da feitiçaria", e não, como poderíamos esperar, da crença na feitiçaria, parece indicar a ambiguidade com que mesmo as hierarquias superiores da igreja católica angolana, responsáveis pela sua redação, olham para a "realidade" do kindoki.

4 O papel das instituições católicas e da atividade missionária na problemáticas das acusações de feitiçaria a crianças continua a levantar questões e a ser escrutinado não só pela antropologia, como também pelos próprios estudos da missionação. Exemplo disso é o recente (2020) número especial da publicação On Knowing Humanity (de subtítulo "Anthropological Ethnography and Analysis Through the Eyes of Christian Faith") integralmente dedicado ao tema. (https://okhjournal. org/index.php/okhj/issue/view/7) 
Referências bibliográficas

ATKINSON-SHEPPARD, Sally. 2017. "Street Children and 'Protective Agency': Exploring Young People's Involvement in Organised Crime in Dhaka, Bangladesh". Childhood, XXIV (3):416-429.

BALLET, Jérôme; DUMBI, Claudine \& LALLAU, Benoit. 2014. "Children's Autonomy in Conflict-Affected Countries". In: Caroline Sarojini Hart et al. (orgs.), Agency and Participation in Childhood and Youth: International Applications of the Capability Approach in Schools and Beyond. Londres: Bloomsbury.

BLANES, Ruy. 2017. "The Ndoki Index: Sorcery, Economy, and Invisible Operations in the Angolan Urban Sphere". In: K. Rio K.; M. MacCarthy \& R. Blanes (orgs.), Pentecostalism and Witchcraft: Spiritual Warfare in Africa and Melanesia. Nova York: Palgrave Macmillan. pp. 93-114.

BORDONARO, Lorenzo. 2012. "Agency Does Not Mean Freedom: Cape Verdean Street Children and the Politics of Children's Agency". Children's Geographies, X (4):413426.

BORTOLAMI, Gabriele. 2012. I Bakongo. Società, Tradizioni e Cambiamento in Angola, PhD Dissertation, Università degli Studi di Sassari.

BRAIN, Robert. 1970. "Child Witches". In: Mary Douglas (org.), Witchcraft Confessions and Accusations. Nova York e Londres: Tavistock Press. pp. 161-179.

BRINKMAN, Inge. 2003. "War, Witches and Traitors: Cases from the MPLA's Eastern Front in Angola (1966-1975)". The Journal of African History, XLXV (2):303-325.
CALVÃO, Filipe. 2017. "The Company Oracle: Corporate Security and Diviner-Detectives in Angola's Diamond Mines". Comparative Studies in Society and History, LIX (3):574-599.

CIMPRIC， Aleksandra. 2010. Children Accused of Witchcraft: An Anthropological Study of Contemporary Practices in Africa. Dakar: UNICEF WCARO.

COMAROFF, Jean. 1997. "Consuming Passions: Child abuse, fetishism, and 'The New World Order'", Culture, XVII:7-19.

COMAROFF, Jean \& COMAROFF, John L. (orgs.). 1993. Modernity and its Malcontents: Ritual and Power in Postcolonial Africa. Chicago: University of Chicago Press. . 1999. "Occult Economies and the Violence of Abstraction: Notes from the South African Postcolony". American Ethnologist, XXVI (2):279303.

CONFERENCIA EPISCOPAL DE ANGOLA E SÃO TOMÉ. 2012. "Nota Pastoral sobre a Problemática da Feitiçaria e as suas Implicações na Vida Eclesiástica". In: CEAST, II Assembleia Plenária da Conferência Episcopal de Angola e S. Tomé. Luanda: CEAST.

DE BOECK, Filip. 2000. "Le 'Deuxième Monde' et les 'Enfants-Sorciers'". Politique Africaine, LXXX:32-57. . 2004. "On Being Shege in Kinshasa: Children, the Occult, and the Street". In: Theodore Trefon (org.), Reinventing Order in the Congo: How People Respond to State Failure in Kinshasa. Londres e Nova York: Zed Books. pp. 155-173. 
DE BOECK, Filip \& HONWANA, Alcinda (orgs.). 2005. Makers \& Breakers: Children \& Youth in Postcolonial Africa. Trenton: Africa World Press.

FANCELLO, Sandra \& BONHOMME, Julien. 2018. "L'État et les institutions face à la sorcellerie". Cahiers d'Études Africaines, CCXXXI-CCXXXII (3):573-591.

FISIY, Cyprian \& GESCHIERE, Peter. 1993. "Sorcellerie et Accumulation, Variations Régionales». In : P. Geschiere \& P. Konings (orgs.), Itinéraires d'accumulation au Cameroun. Paris: Karthala. pp. 99130.

FONSECA, António. 1989. Sobre os Kikongos de Angola. Luanda: União dos Escritores Angolanos.

GESCHIERE, Peter. 1995. Sorcellerie et Politique en Afrique: La Viande des Autres. Paris: Karthala.

. 1997. The Modernity of Witchcraft: Politics and the Occult in Postcolonial Africa. Charlottesville: University of Virginia Press.

HANSON, Karl \& RUGGIERO, Roberta. 2013. Child Witchcraft Allegations and Human Rights. Briefing paper para o Subcomité de Direitos Humanos do Parlamento Europeu. Bruxelas: Parlamento Europeu.

HONWANA, Alcinda. 2002. "Negotiating Postwar Identities: Child Soldiers in Mozambique and Angola". In: George Bond \& Nigel Gibson (orgs.), Contested Terrains and Constructed Categories. Boulder: Westview Press. pp. 277-298.

. 2005. "Innocent and Guilty: Child-soldiers as Interstitial and Tactical Agents". In: Filip de Boeck \& Alcinda Honwana (orgs.), Makers and Breakers: Children and Youth in Postcolonial Africa. Trenton: Africa World Press. pp. 31-52.
HORNA PADRÓN, Marisa \& BALLET, Jérôme. 2011. "Child Agency and Identity: The Case of Peruvian Children in a Transitional Situation". In: Mario Biggeri et al. (orgs.), Children and the Capability Approach. Nova York: Palgrave Macmillan. pp. 162-174.

HUMAN RIGHTS WATCH. 2012. "'Se Voltarem, Vamos Matar-vos': Violência Sexual e Outros Abusos Cometidos Contra Imigrantes Congoleses Durante as Expulsões de Angola". Disponível em: https://www. hrw.org/pt/report/2012/05/21/256322. Acesso em 15/07/2019).

2013. "'Tira Essas Porcarias Daqui': Violência Policial Contra Vendedoras Ambulantes em Angola". Disponível em: https://www.hrw.org/ pt/report/2013/09/30/256474. Acesso em 15/07/2019.

JAMES, Allison \& PROUT, Alan (orgs.). 1990. Constructing and Reconstructing Childhood. Contemporary Issues in the Sociological Study of Childhood. Basingstoke: Falmer Press.

KLOCKER, Natascha. 2007. "An Example of Thin Agency: Child Domestic Workers in Tanzania". In: Ruth Panelli, Samantha Punch \& Elsbeth Robson (orgs.), Global Perspectives on Rural Childhood and Youth: Young Rural Lives. Londres: Routledge. pp. 83-94.

KROESBERGEN-KAMPS, Johanneke. 2020. "Witchcraft after modernity: Old and new directions in the study of witchcraft in Africa". Hau: Journal of Ethnographic Theory, X (3):860-873. LA FONTAINE, Jean (org.). 2016. The Devil's Children. From spirit possession to witchcraft: New allegations that affect children. Abingdon: Routledge. 
LA HAUSSE, Paul. 1990. "The Cows of Nongoloza: Youth, crime, and Amalaita gangs in Durban, 19001930". Journal of Southern African Studies, XVI (1):79-111.

MACGAFFEY, Wyatt. 1974. "Oral Tradition in Central Africa". The International Journal of African Historical Studies, VII (3):417-426.

MARWICK, Max. 1964. "Witchcraft as Social Strain-gauge", Australian Journal of Science, XXVI:263-268.

MATA MOURISCA, Francisco de. 2003. Política da Feitiçaria. Mbanza Kongo: Diocese de Mbanza Kongo.

MEYER, Birgit. 1992. "'If You Are a Devil, you Are a Witch and, if you Are a Witch, you Are a Devil': The integration of 'pagan' ideas into the conceptual universe of the Ewe Christians in Southeastern Ghana". Journal of Religion in Africa, XXII (2):98-132.

MILANDO, João. 2007. "Atores Invisíveis do Desenvolvimento em África: O Kindoki na racionalização dos comportamentos no meio rural de Cabinda (Angola)". Cadernos de Estudos Africanos, XIII/XIV:81-98.

NEVES, Tony. 2012. Angola: Justiça e Paz nas Intervenções da Igreja Católica (1989-2002). Lisboa: Texto Editora.

NZATUZOLA, João Baptista. 1997. "Aspectos de algumas características e manifestações de migrações em Luanda". Africana, XVIII:105-125.

OLIVEIRA, Ricardo Soares de. 2007. "Business Success, Angola-style: Postcolonial politics and the rise and rise of Sonangol". Journal of Modern African Studies, XLV (4):595-619.

PARISH, Jane. 2000. "From the Body to the Wallet: Conceptualizing Akan witchcraft at home and abroad", Journal of the Royal Anthropological Institute, VI (3):487-500.
PARSONS, Imogen. 2004. "Youth, Conflict and Identity: Political Mobilisation and Subjection in Angola". In: Angela McIntyre (org.), Invisible Stakeholders: Children and War in Africa. Pretoria: Institute for Security Studies. pp. 45-66.

PEREIRA, Luena. 2008. "Crianças Feiticeiras: Reconfigurando família, igrejas e Estado no pós-guerra angolano". Religião \& Sociedade, XXVIII (2):30-55.

. 2011. "Families, Churches, the State, and the Child Witch in Angola". In: Luis Nicolau Parés \& Roger Sansi (orgs.), Sorcery in the Black Atlantic. Chicago: University of Chicago Press. pp. 187-208.

PÉREZ, Helena. 2006. O Impacto das Acusações de Feitiçaria contra Crianças em Angola: Uma Análise na Perspetiva da Proteção dos Direitos Humanos. Luanda: INAC/UNICEF.

PIOT, Charles. 2010. Nostalgia for the Future: West Africa after the Cold War. Chicago e Londres: Chicago University Press.

PIROT, Bernard. 2004. Enfants des Rues d'Afrique Centrale (Douala et Kinshasa): De l'Analyse à l'Action. Paris: Karthala.

RODRIGUES, Cristina Udelsmann. 2010. "Youth in Angola: Keeping the pace towards modernity". Cadernos de Estudos Africanos, XVIII/XIX:165179.

ROWLANDS, Michael \& WARNIER, Jean-Pierre. 1988. "Sorcery, Power, and the Modern State in Cameroon". Man - The Journal of the Royal Anthropological Institute, XXIII:118-32.

SARRÓ, Ramon; BLANES, Ruy \& VIEGAS, Fátima. 2008. «La Guerre en temps de Paix. Ethnicité et Angolanité dans l'Église Kimbanguiste de Luanda». Politique Africaine, CX:84101. 
SCHEPER-HUGHES, Nancy. 1996. "Theft of Life: The globalization of organ stealing rumours". Anthropology Today, XII (3):3-10.

SHEPLER, Susan. 2005. "The Rites of the Child: Global discourses of youth and reintegrating child soldiers in Sierra Leone". Journal of Human Rights, IV (2):197-211.

THE NATIONAL WORKING GROUP ON CHILD ABUSE LINKED TO FAITH OR BELIEF. 2012. National Action Plan to Tackle Child Abuse Linked to Faith or Belief. Londres: Department of Education.

TOMÁS, António Andrade. 2012. Refracted Governmentality: Space, politics and social structure in contemporary Luanda. PhD Dissertation, Nova York, Graduate School of Arts and Sciences, Columbia University.

UNGRUHE, Christian. 2019. "Beyond Agency's Limits. Street Children's Mobilities in Southern Ghana". Cadernos de Estudos Africanos, XXXVII:41-61.

VAN DER MEER, Erwin. 2013. "Child witchcraft accusations in Southern Malawi". The Australasian Review of African Studies, XXXIV (1):129-144. YENGO, Patrice. 2008. "Le Monde à l'Envers: Enfance et kindoki ou les ruses de la raison sorcière dans le basin du Congo». Cahiers d'Études Africaines, CLXXXIX/CXC:297-323. 
“ÉS FEITICEIRO, ENTÃO JÁ

ESTUDAS" : CRIANÇAS EM RISCO, AGENCIALIDADE E MOBILIDADE SOCIAL EM ANGOLA

Resumo

Este trabalho explora o papel da feitiçaria - e em particular das acusações dirigidas a crianças - nas reconfigurações sociais que têm marcado, desde 2002, o pósguerra civil em Angola. Destaca, por um lado, a forma como a problemática social das "crianças-feiticeiras" se articula intimamente com a etnopolítica bakongo e com o debate sobre o lugar desta etnia na sociedade angolana; por outro, revela que, longe de serem elementos passivos nesse processo, as próprias crianças podem instrumentalizar as acusações como forma de aceder a recursos e oportunidades que lhes permitam ascender socialmente. Desta forma, vai ao encontro de outros estudos que, nas últimas décadas, identificam transformações profundas no estatuto da infância e juventude em vários contextos de crise pós-Guerra Fria na África Ocidental. Este trabalho partiu de uma etnografia dos processos de reintegração social e familiar de crianças acusadas de feitiçaria acolhidas em instituições missionárias católicas na capital, Luanda, e em Mbanza Kongo, na província angolana do Zaire.

Palavras-chave: Crianças-feiticeiras, Juventude, Missões, Angola, Feitiçaria, Agencialidade.

\author{
“YOU'RE A WITCH, YOU'RE ABLE \\ TO STUDY": CHILDREN AT RISK, \\ AGENCY AND SOCIAL MOBILITY IN \\ ANGOLA
}

\section{Abstract}

This article explores the role of witchcraft, and in particular of accusations directed against children, in the social reconfigurations that, since 2002, have characterized the post-civil war period in Angola. On the one hand, it highlights the way in which the "witch children" phenomenon, perceived as a social problem, is closely related to bakongo ethnopolitics and with the debate on the place of this ethnic group in Angolan society. On the other, it reveals that, far from being passive elements in this process, children can themselves use accusations as a way to access resources and opportunities that allow them to ascend socially. In this way, the article echoes other studies which, in the last few decades, have identified profound transformations in the status of children and young people in different contexts of the post-Cold War crisis in West Africa. It starts from an ethnography of the social and family reintegration processes of children accused of witchcraft sheltered at Catholic missionary institutions in the capital, Luanda, and Mbanza Kongo, in the Angolan province of Zaire.

Keywords: Child-witches; Youth; Missions; Angola; Witchcraft; Agency. 


\section{“ERES UN HECHICERO, ENTONCES \\ YA ESTUDIAS": NIÑOS EN RIESGO, AGENCIA Y MOVILIDAD SOCIALEN ANGOLA}

\section{Resumen}

Este trabajo explora el papel de la hechicería, y en particular de las acusaciones dirigidas hacia niños, en las reconfiguraciones sociales que han marcado, desde 2002, el posguerra civil en Angola. Destaca, por un lado, cómo los problemas sociales de los "niños hechiceros" están estrechamente vinculados con la etnopolítica Bakongo y con el debate sobre el lugar de este grupo étnico en la sociedad angoleña; por otro lado, revela que, lejos de ser elementos pasivos en este proceso, los propios niños pueden usar las acusaciones como una forma de acceder a recursos y oportunidades que les permiten ascender socialmente. De esta manera, el presente artículo dialoga con otros estudios que, en las últimas décadas, han identificado profundas transformaciones en el status de los niños y jóvenes en diversos contextos de la África Occidental durante la crisis que siguió a la Guerra Fría. Este trabajo partió de una etnografía de los procesos de reintegración social y familiar de los niños acusados de hechicería recibidos en instituciones misioneras católicas en la capital, Luanda, y en Mbanza Kongo, en la provincia angoleña de Zaire.

Palabras clave: Niños hechiceros; Juventud; Misiones; Angola; Hechicería; Agencia. 